\title{
Acidic stress promotes a glioma stem cell phenotype
}

\author{
AB Hjelmeland ${ }^{\star,},{ }^{1}, Q$ Wu$^{1}$, JM Heddleston ${ }^{1}$, GS Choudhary ${ }^{2}$, J MacSwords ${ }^{1}$, JD Lathia ${ }^{1}$, R McLendon ${ }^{3}$, D Lindner ${ }^{4}$, A Sloan ${ }^{5}$ and JN Rich $^{\star, 1}$
}

Malignant gliomas are lethal cancers that display cellular hierarchies with cancer stem cells at the apex. Glioma stem cells (GSCs) are not uniformly distributed, but rather located in specialized niches, suggesting that the cancer stem cell phenotype is regulated by the tumor microenvironment. Indeed, recent studies show that hypoxia and its molecular responses regulate cancer stem cell maintenance. We now demonstrate that acidic conditions, independent of restricted oxygen, promote the expression of GSC markers, self-renewal and tumor growth. GSCs exert paracrine effects on tumor growth through elaboration of angiogenic factors, and low pH conditions augment this expression associated with induction of hypoxia inducible factor $2 \alpha$ (HIF2 $\alpha$ ), a GSC-specific regulator. Induction of HIF2 $\alpha$ and other GSC markers by acidic stress can be reverted by elevating pH in vitro, suggesting that raising intratumoral pH may be beneficial for targeting the GSC phenotype. Together, our results suggest that exposure to low $\mathrm{pH}$ promotes malignancy through the induction of a cancer stem cell phenotype, and that culturing cancer cells at lower $\mathrm{pH}$ reflective of endogenous tumor conditions may better retain the cellular heterogeneity found in tumors.

Cell Death and Differentiation (2011) 18, 829-840; doi:10.1038/cdd.2010.150; published online 3 December 2010

Malignant gliomas are intrinsic brain tumors without current cures. ${ }^{1}$ The prognosis for a grade IV glioma (glioblastoma; GBM) is less than 14-months survival after diagnosis, even with maximal surgical resection, radiation and chemotherapy. ${ }^{2}$ The poor outcome for malignant glioma patients is largely due to tumor recurrence post treatment, often within $3 \mathrm{~cm}$ of the original site. ${ }^{1}$ Recurrence may be due to the survival of a sub-population of glioma cells that drive tumor growth. These tumor-initiating cells have some characteristics of normal neural stem cells, including the expression of stem cell markers and the ability to self-renew, and are therefore called glioma stem cells (GSCs). GSCs have been shown to be highly tumorigenic, pro-angiogenic and resistant to therapy compared with the majority of tumor cells, suggesting the importance of targeting GSCs for novel glioma therapies. ${ }^{3,4}$

Immunohistochemistry of human specimens has revealed that GSCs are highly prevalent in specific niches within the glioma rather than being equally distributed throughout the tumor. $^{5-7}$ These data suggest that microenvironmental conditions present in solid tumors can be critical for the regulation of molecular and biological properties of GSCs. Indeed, data from our laboratory and others demonstrated that exposure to low-oxygen tension or hypoxia-a common microenvironmental condition in solid tumors-increases expression of cancer stem cell markers including CD133 and HIF2 $\alpha^{6-9}$ Demonstration that hypoxia can influence the GSC phenotype led to GSC paradigms incorporating extrinsic factors and tumor-cell plasticity. ${ }^{8-10}$ These more dynamic, rather than strictly hierarchical, models suggest that understanding the
GSC microenvironment may offer new avenues for therapeutic intervention.

An important tumor microenvironment that has yet to be evaluated in the context of the GSC paradigm is $\mathrm{pH}$. For a wide variety of cancers, extracellular solid tumor $\mathrm{pH}$ has been determined to be significantly more acidic than in normal tissues and may decrease as tumor size increases. ${ }^{11-15}$ Tumor $\mathrm{pH}$ can be highly variable within one tumor with localized regions of acidity. ${ }^{11,13}$ Electrode measurements of $\mathrm{pH}$ in human brain tumors have been as low as 5.9 with a mean around 6.8, whereas normal brain tissue has a $\mathrm{pH}$ of $\sim 7.1{ }^{12}$ Although an acidic microenvironment is often considered to be integrally linked with hypoxia, in vivo glioma xenograft studies demonstrated the presence of oxygenated, but acidic brain tumor regions, ${ }^{16}$ suggesting the potential for independent effects of hypoxia and low $\mathrm{pH}$. Together, these data demonstrate that acidic stress is an established microenvironmental component of gliomas.

An acidic $\mathrm{pH}$ shift within solid tumors can regulate multiple biological processes: these include proliferation, angiogenesis, immunosuppression, invasion and chemoresistance. ${ }^{11-15}$ In gliomas, low $\mathrm{pH}$ may increase angiogenesis through the induction of vascular endothelial growth factor (VEGF)..$^{16,17}$ Reduced extracellular $\mathrm{pH}$ also increased the resistance of glioma cells to multiple drugs including topotecan and cisplatin, ${ }^{18}$ although cell growth was decreased. ${ }^{18,19}$ As several of these $\mathrm{pH}$-regulated biologies are also characteristically driven by GSCs, we sought to determine the effect of an acidic microenvironment on the GSC phenotype.

\footnotetext{
${ }^{1}$ Departments of Stem Cell Biology and Regenerative Medicine, Cleveland Clinic, Cleveland, OH, USA; ${ }^{2}$ Department of Biomedical Science, Case Western Reserve University, Cleveland, OH, USA; ${ }^{3}$ Department of Pathology, Duke University, Durham, NC, USA; ${ }^{4}$ Department of Cancer Biology, Cleveland Clinic, Cleveland, OH, USA and ${ }^{5}$ Department of Neurosurgical Oncology, Case Western Reserve University, Cleveland, OH, USA

*Corresponding authors: AB Hjelmeland or JN Rich, Department of Stem Cell Biology and Regenerative Medicine, Cleveland Clinic, 9500 Euclid Avenue, Mailstop NE30, Cleveland, OH 44195, USA. Tel: + 1216636 1667; Fax: + 1216636 5454; E-mail: hjelmea@ @cc.org (AB Hjelmeland); Tel: + 12166361010 ;

Fax: + 1216636 5454; E-mail: richj@ccf.org (JN Rich)

Keywords: $\mathrm{pH}$; acidic microenvironment; glioma; cancer stem cell

Abbreviations: DFX, desferrioxamine; DMEM, Dulbecco's Modified Eagle Medium; EGF, epidermal growth factor; ELISA, enzyme-linked immunosorbent assay; FBS, fetal bovine serum; FGF, fibroblast growth factor; GBM, glioblastoma; GFAP, glial fibrillary acidic protein; GSC, glioma stem cell; HIF, hypoxia inducible factor; PCR, polymerase chain reaction; IL-8, interleukin 8; TIMP, tissue inhibitor of metalloproteinase; VEGF, vascular endothelial growth factor

Received 03.8.10; revised 01.10.10; accepted 12.10.10; Edited by R De Maria; published online 03.12.10
} 
We provide evidence here for the first time that exposure to low $\mathrm{pH}$ promotes the expression cancer stem cell markers, self-renewal and tumorigenesis: hallmarks of GSCs.

\section{Results}

Tissue pH decreases in human glioma xenografts. The majority of experiments to determine the effects of an acidic microenvironment utilize $\mathrm{pH}$ 6.4-6.6 in vitro, although in vivo glioma $\mathrm{pH}$ has been measured to be as low as $\mathrm{pH}$ 5.9. ${ }^{12,13,18,19}$ To evaluate whether low $\mathrm{pH}$ could have a physiologically relevant influence on the CSC phenotype, we first determined the $\mathrm{pH}$ levels in the microenvironment of human glioma xenografts from which GSCs were derived. When extracellular $\mathrm{pH}$ was measured with an electrode probe, we observed a significant decrease in $\mathrm{pH}$ at the edge of the tumor compared with normal tissue (Supplementary Figure 1). The intratumoral extracellular $\mathrm{pH}$ at the center of the glioma xenograft was even further decreased when compared with the tumor edge (Supplementary Figure 1). These data strongly suggest that low $\mathrm{pH}$ is an important component of the in vivo tumor microenvironment to which GSCs are exposed.

Exposure to low pH maintains and promotes expression of glioma stem cell markers. To elucidate whether acidic stress could influence the phenotype of GSCs, isolated GSCs were exposed to standard $\mathrm{pH}(7.5)$ or an acidic $\mathrm{pH}$ (6.5). Cells grown in low pH conditions displayed a consistent increase in cancer stem cell markers including Olig2, Oct4 and Nanog (Figures 1a-c; Supplementary Figure 2), but not Sox2 (data not shown). Olig2 mRNA was significantly induced greater than fourfold in all preparations of GSCs tested (Figure 1a; Supplementary Figure 2A), whereas Oct4 and Nanog were usually increased greater than twofold (Figures 1b and c; Supplementary Figure 2B). To determine whether these increases in stem cell markers represented a greater ability to maintain the cancer stem cell phenotype, GSCs were placed in normal or acidic media containing serum to stimulate differentiation. In the presence of serum, GSCs cultured at $\mathrm{pH} 7.5$ acquired expression of the astrocyte marker glial fibrillary acidic protein (GFAP), whereas exposure to acidic conditions prevented GFAP expression (Figure 1d; Supplementary Figure 3). These data suggest that low $\mathrm{pH}$ may prevent terminal differentiation and facilitate cancer stem cell maintenance.

We next sought to determine whether exposure to acidic conditions would promote expression of GSC markers in cultures initially depleted of GSCs. Similar to the results in GSCs, we found that mRNA expression of Olig2, Oct4 and Nanog increased when cells were treated with media at $\mathrm{pH} 6.5$ relative to $\mathrm{pH} 7.5$ (Figures $2 \mathrm{a}-\mathrm{c}$; Supplementary Figure 4). However, the induction of stem cell markers was often more potent in GSC-depleted cultures (Figures 2a-c; Supplementary Figure 4) than effects in GSCs (Figures 1a-c; Supplementary Figure 2). Treatment with low $\mathrm{pH}$ significantly induced Olig2 greater than eightfold in comparison with standard culture $\mathrm{pH}$ in several preparations of GSC-depleted cultures (Figure 2a; Supplementary Figure 4A). Similarly,
Oct4 was increased greater than sixfold (Figure 2b) and Nanog was increased at least sevenfold in all samples tested (Figure 2c; Supplementary Figure 4B). Using immunofluorescence, we confirmed that cells treated with low $\mathrm{pH}$ had increased expression of Nanog protein when compared with cells passaged under a typical culture pH (Figure 2d; Supplementary Figure 5). Consistent with these findings, culture in acidic conditions was associated with minimal expression of differentiation markers (Figures 2 and 3; Supplementary Figure 5). The astrocyte differentiation marker GFAP (Figure 2d; Supplementary Figure 5) and the neuronal differentiation marker class III $\beta$-tubulin (Tuj1; Figure 3) are decreased in cells exposed to $\mathrm{pH}$ 6.5. In contrast, GFAP and Tuj1 are highly prevalent in GSC-depleted cells under typical cell culture conditions (Figures $2 \mathrm{~d}$ and 3 Supplementary Figure 5). Furthermore, bulk glioblastoma cells isolated directly from a patient specimen and exposed to acidic stress had increased percentages of CD133 + cells (Supplementary Figure 6). These data demonstrate that reductions in $\mathrm{pH}$ increase expression of GSC markers while decreasing differentiation marker expression.

Acidic stress promotes functional indicators of the glioma stem cell phenotype. We next sought to determine whether the changes in GSC markers upon low $\mathrm{pH}$ could be sufficient to influence the cellular behaviors of neurosphere formation and tumorigenic capacity associated with GSCs. We noted morphological changes on exposure to acidic conditions (but not typical culture $\mathrm{pH}$ ) consistent with the acquisition of neurosphere-like structures when identical cell numbers were plated (Figures $3 a$ and $4 a$ ). These morphological changes appeared to be indicative of the acquisition of greater neurosphere formation capacity, as the percentage of wells with neurospheres significantly increased with low $\mathrm{pH}$ treatment (Figure 4b). We then sought to determine whether the elevation of this artificial indicator of self-renewal in vitro was consistent with promotion of tumor formation in vivo. When mice were intracranially implanted with cells exposed to acidic stress, the survival of mice bearing human glioma xenografts was increased in comparison with cells cultured under typical pH (Figure 4c). Similarly, we observed an increase in the size of subcutaneous tumors initiated with low $\mathrm{pH}$ treated cells with a trend towards statistical significance (Figure 4d). Immunohistochemical analysis of intracranial (Figure $4 \mathrm{e}$; Supplementary Figure 7) and subcutaneous (data not shown) tumors suggested that gliomas originating from cells exposed to acidic stress had increased microvascular density and volume. Although these data support the notion that acidic $\mathrm{pH}$ promotes a pro-angiogenic GSC-driven microenvironment, tumor vessel density depends on the metabolic requirements of the growing tumor. Thus, differences in tumor size and location will directly influence the development of the glioma vasculature post-initiation.

Low $\mathrm{pH}$ induces expression of angiogenic factors in human glioma cells. The tumorigenic capacity of GSCs is due, in part, to an ability to promote angiogenesis associated with increased production of vascular endothelial growth factor (VEGF). ${ }^{20}$ VEGF levels increase in acidic cell 
a

GSC Enriched

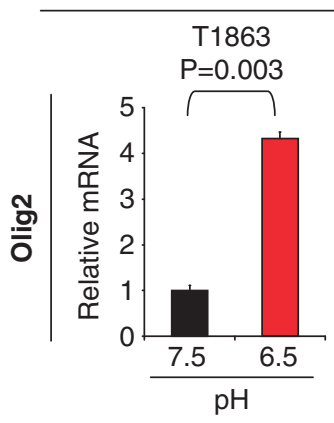

T4302
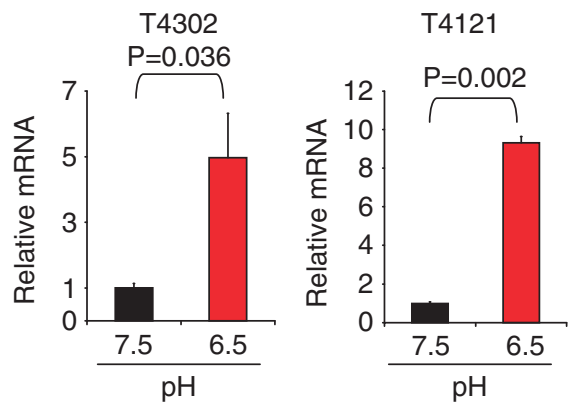

b

T4302

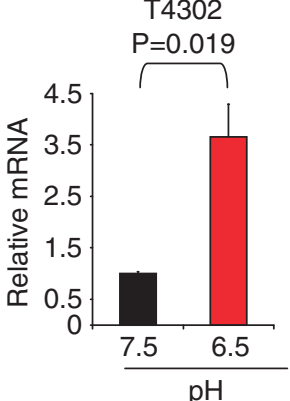

T4121
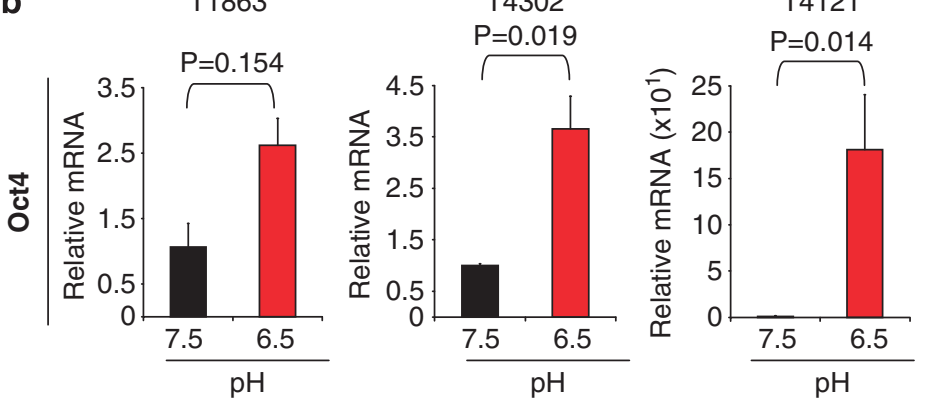

C

$\mathrm{T} 1863$
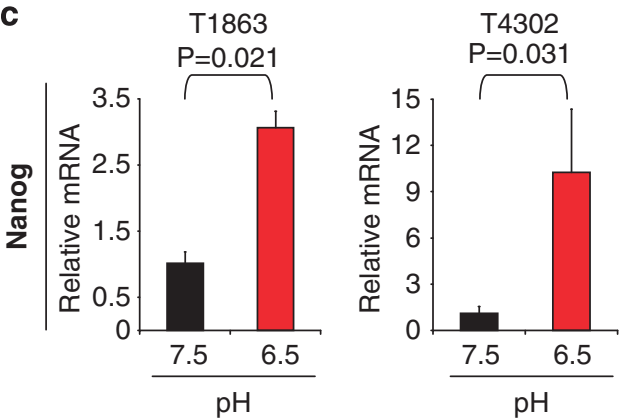

T4121

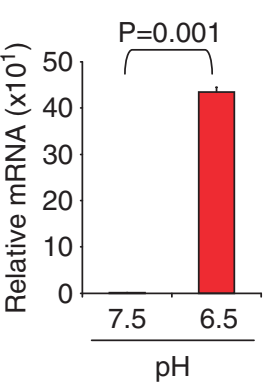

d

GFAP

DAPI
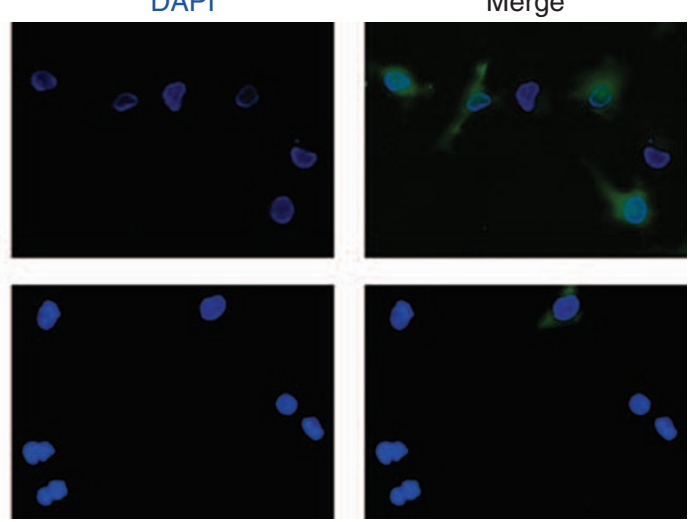

Figure 1 Cancer stem cell markers are maintained in acidic GSC-enriched cultures. (a-c) Expression of cancer stem cell markers was evaluated in CD133 + cells isolated from three different human glioma xenografts and subsequently treated with acidic (pH 6.5) or normal (pH 7.5) cell culture media for 6 days. RNA was collected using Qiagen RNAeasy kits, reverse transcribed and analyzed for the specific genes indicated using real-time PCR. $n=2$ for each tumor type. (a) Treatment with low pH increased expression of Olig2 mRNA in T1863, T4302 and T4121 GSC-enriched cultures. (b) Exposure to reduced pH increased expression of Oct4 mRNA in T1863, T4302 and T4121 GSCs. (c) Acidic stress increased expression of Nanog mRNA in T1863, T4302 and T4121 GSCs. (d) All GSCs shown were cultured in the presence of serum to induce differentiation. Immunofluorescence for the astrocyte marker glial fibrillary protein (GFAP, green) and the nuclear stain DAPI (blue) demonstrates the presence of the differentiation cell marker GFAP in glioma stem cells cultured at pH 7.5. In contrast, GFAP is rarely expressed in cells exposed to acidic stress 
a
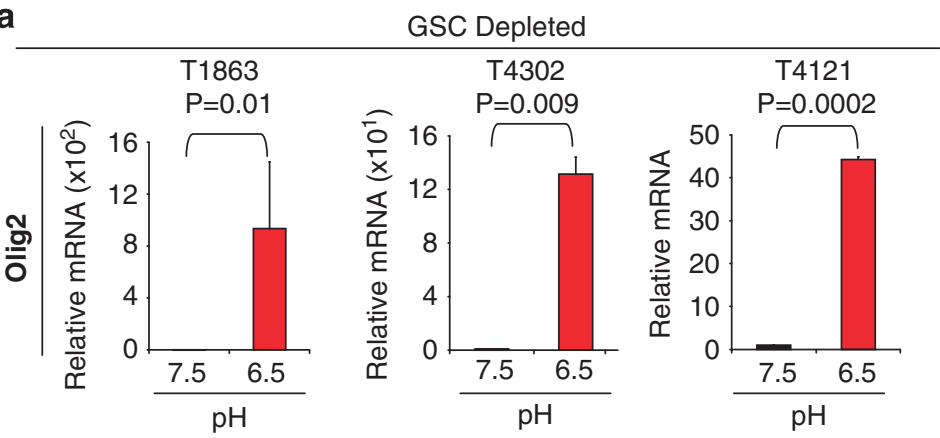

b

T1863
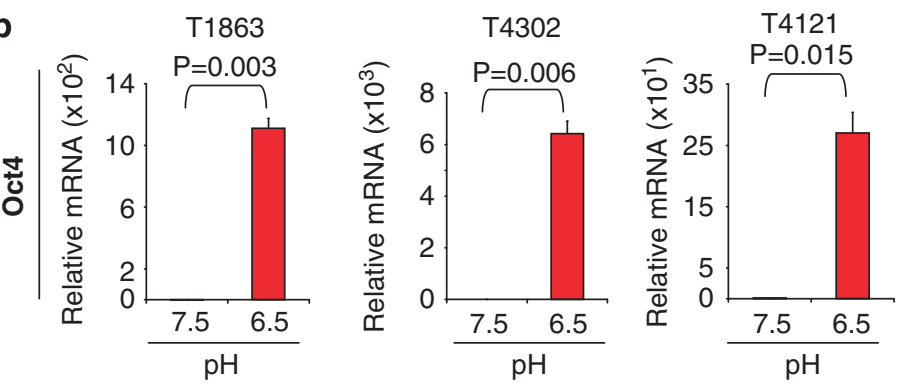

c
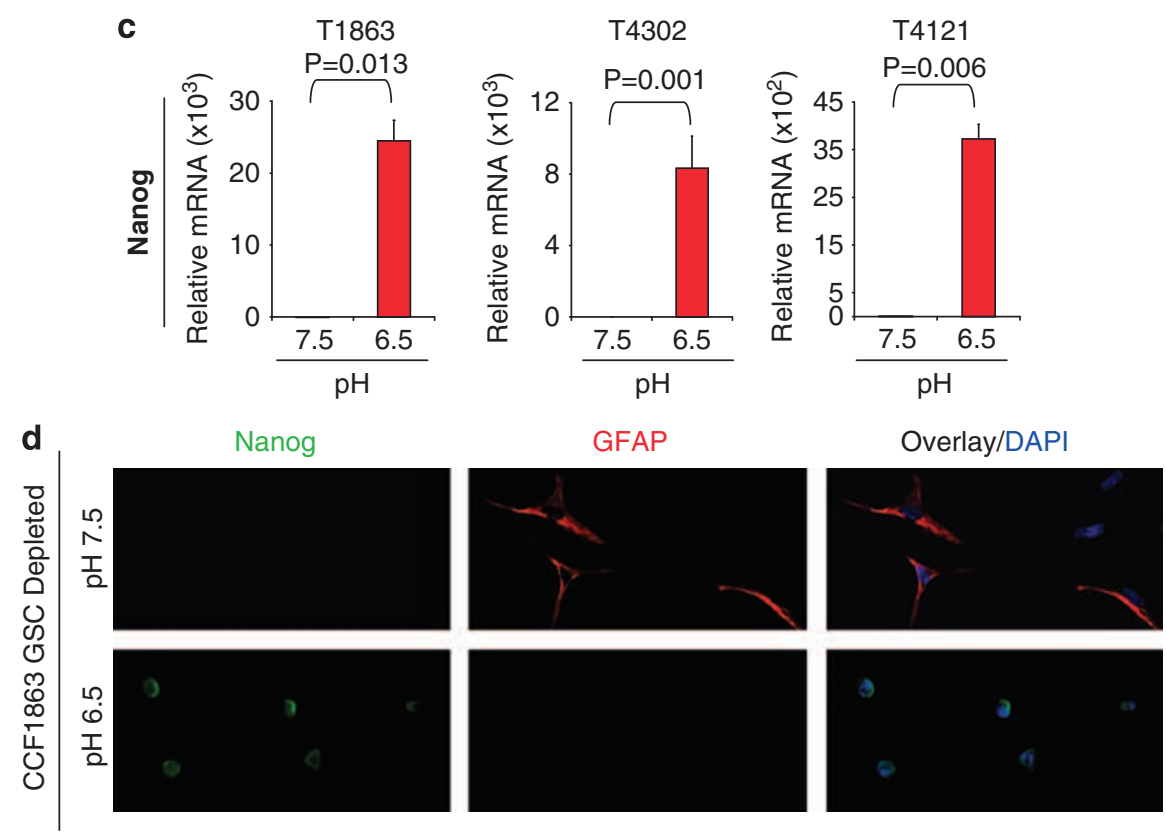

Figure 2 Cancer stem cell markers increase in GSC-depleted cultures after treatment with low pH. (a-c) Expression of cancer stem cell markers was evaluated in $\mathrm{CD} 133$ - cells isolated from three different human glioma xenografts and subsequently cultured under low pH (6.5) or typical cell culture conditions (pH 7.5) for 6 days. RNA was collected using Qiagen RNAeasy kits, reverse transcribed, and analyzed for the specific genes indicated using real-time PCR. $n=2$ for each tumor type. (a) Treatment with low pH increased expression of Olig2 mRNA in T1863, T4302 and T4121 GSC-depleted cultures. (b) Exposure to low pH increased expression of Oct4 mRNA in T1863, T4302 and T4121 GSC-depleted cultures. (c) Acidic stress increased expression of Nanog mRNA in T1863, T4302 and T4121 GSC-depleted cultures. (d) Immunofluorescence for the stem cell marker Nanog (green), astrocyte marker glial fibrillary protein (GFAP, red) and the nuclear stain DAPI (blue) demonstrates the presence of Nanog in cells cultured at pH 6.5. In contrast, the differentiation marker GFAP is highly present in cells cultured at pH 7.5, but rarely when cells were exposed to $\mathrm{pH} 6.5$

culture, ${ }^{16,17}$ suggesting that VEGF could be an important component of the low $\mathrm{pH}$-driven CSC phenotype. To determine the effect of an acidic microenvironment on GSC secretion of a panel of angiogenic factors including VEGF, we collected conditioned media from cells pre-cultured in normal cell culture conditions or under low $\mathrm{pH}$. Using the GSC conditioned media from $\mathrm{pH} 7.5$ treated cells with human angiogenesis protein arrays, expression of VEGF, interleukin 8 (IL-8) and tissue inhibitors of metalloproteinases (TIMP1, TIMP2) was readily detected at the baseline. Exposure to $\mathrm{pH} 6.5$ further increased expression of IL-8 and VEGF (Figure 5a). Quantification of the changes in VEGF secretion by GSCs using the angiogenesis array and Image $\mathrm{J}$ software (NIH, rsbweb.nih.gov/ij) revealed an approximately 
a

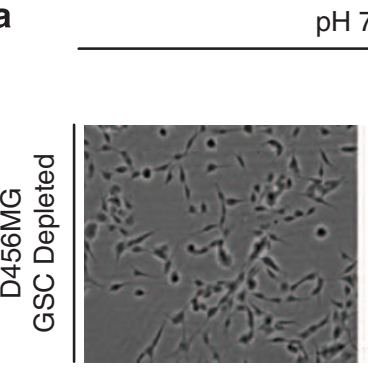

b

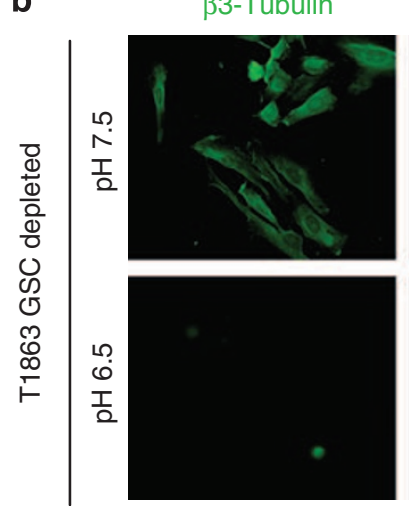

c

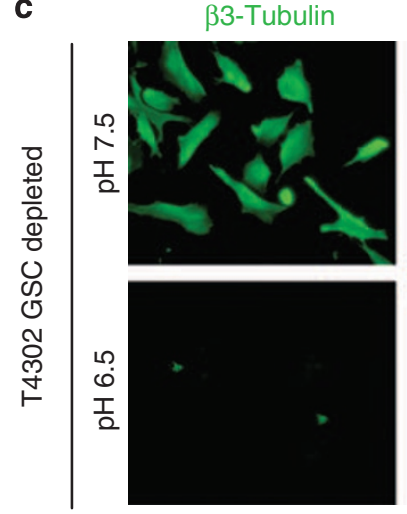

d

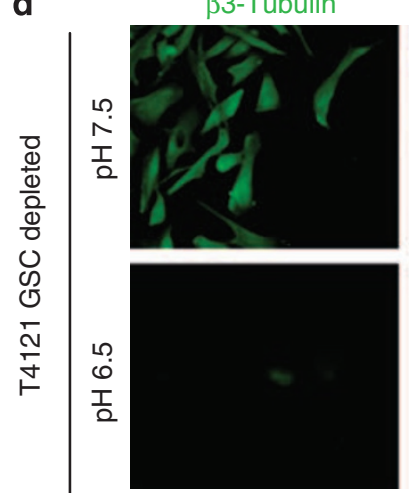

$\mathrm{pH} 7.5$

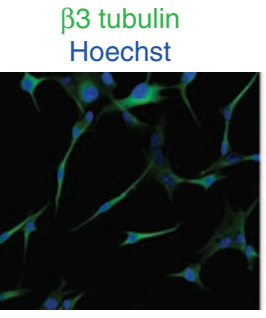

DAPI
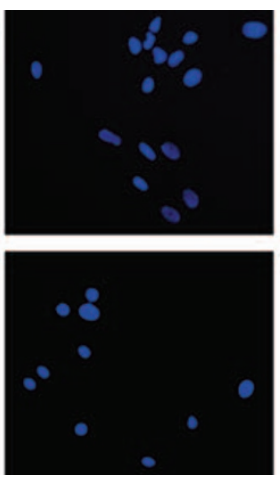

DAPI
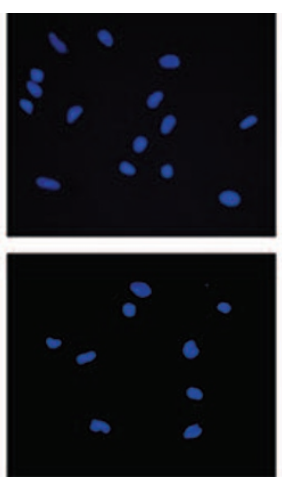

DAPI
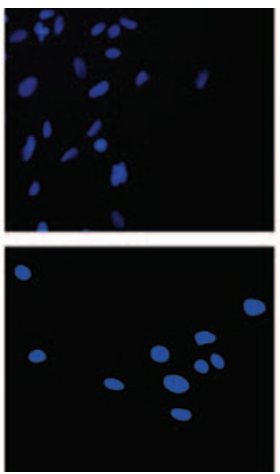

pH 6.5
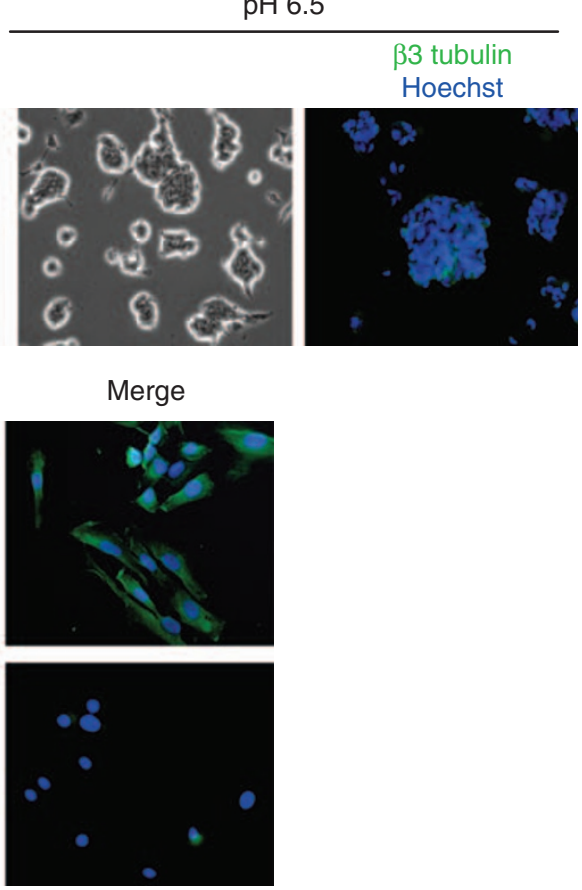

Merge
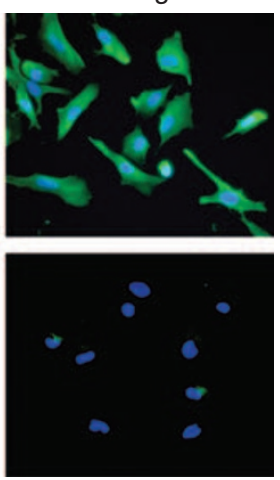

Merge
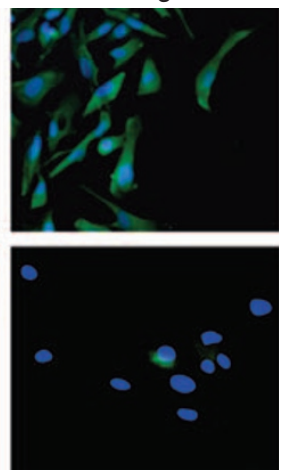

Figure 3 Reduced differentiation marker expression in GSC-depleted cultures after exposure to acidic stress. (a) Immunofluorescence for the neuronal differentiation marker class III $\beta$-tubulin (green) and the nuclear stain Hoescht (blue) demonstrates that class III $\beta$-tubulin is highly present in cells cultured at $\mathrm{pH} 7.5$, but rarely present when CD133- D456 MG cells were exposed to pH 6.5. Immunofluorescence for $\beta$ III tubulin (green) and the nuclear stain DAPI (blue) in T1863 (b), T4302 (c), and T4121 (d) CD133 - cells demonstrates reduced neuronal differentiation marker expression after acidic stress

threefold increase in VEGF levels upon low $\mathrm{pH}$ treatment (Figure 5b). A similar fold increase in secreted VEGF with acidic conditions was detected using ELISA (Figure 5c).
These data demonstrate that GSCs exposed to low $\mathrm{pH}$ produce elevated levels of secreted factors, which have the capacity to modulate tumor growth. 
a

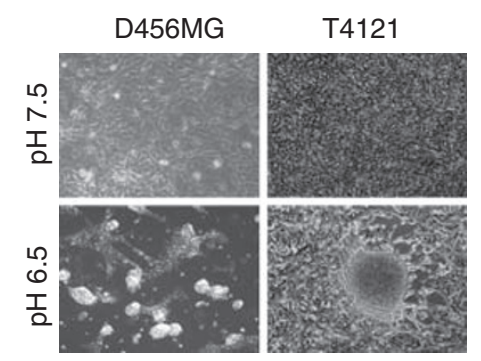

C

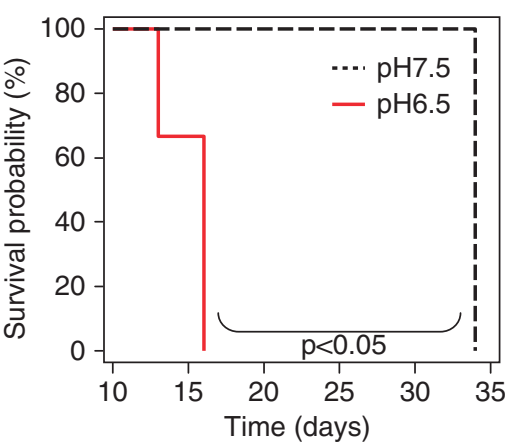

e

$H \& E$

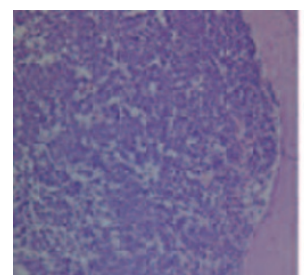

$\mathrm{pH} 7.5$

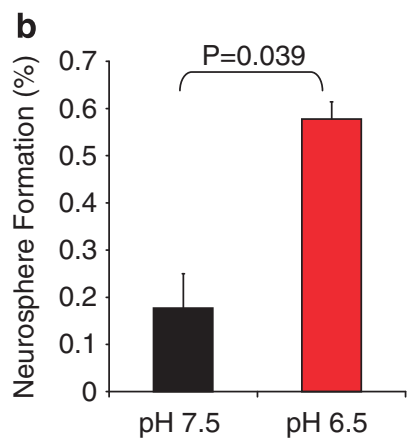

d
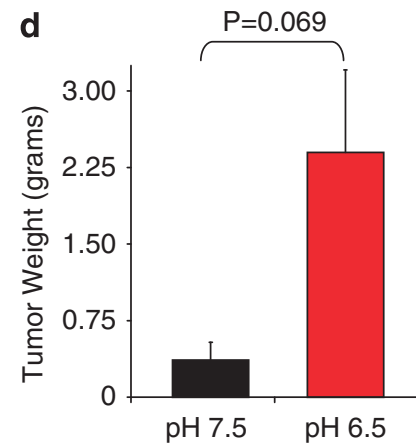

$H \& E$
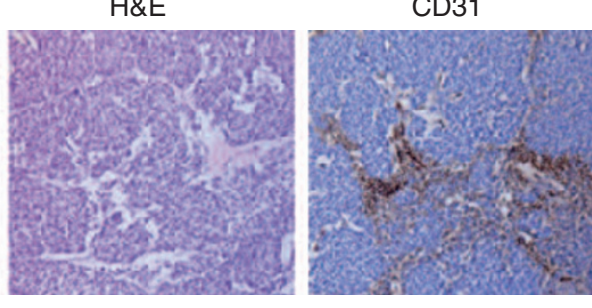

$\mathrm{pH} 6.5$

Figure 4 Functional indicators of the increase in GSC-depleted cultures after treatment with low pH. Expression of cancer stem cell markers was evaluated in CD133cells isolated from three different human glioma xenografts and subsequently cultured with acidic (pH 6.5) or normal (pH 7.5) media for 14 days. (a) Representative images of D456 MG and T4121 GSC-depleted cultures with and without low pH. (b) The percentage of wells with neurospheres increases with low-pH treatment. D456 MG cells pretreated with $\mathrm{pH} 6.5$ or $\mathrm{pH} 7.5$ media were plated using flow cytometry with five cells per well and the percentage of wells with neurospheres was determined after 10 days. $n=2$. (c) Kaplan-Meier Curves demonstrate the survival of mice ( $n=3$ for each arm) bearing human glioma xenografts generated from D456 MG cells pretreated with $\mathrm{pH} 6.5$ or $\mathrm{pH}$ 7.5. Survival is significantly reduced when xenografts originate from cells treated with low $\mathrm{pH}$. (d) Growth of subcutaneous human glioma xenografts $(n=3$ for each arm) is increased with a trend towards statistical significance when cells are exposed to low $\mathrm{pH}$ in comparison with standard pH. (e) Representative images of tumors harvested from (c) and subsequently sectioned and stained with hematoxylin and eosin (H\&E) or CD31 to indicate blood vessels

To determine whether the effect of acidic stress on angiogenic factors was equivalently prevalent in the majority of tumor cells, we performed identical experiments with cultures initially depleted of GSCs. Using the angiogenesis array, we found that low pH potently increased levels of IL-8, TIMP1, TIMP2 and VEGF (Figure $5 \mathrm{~d}$ ). The intensity of VEGF staining on the angiogenesis array increased approximately threefold (Figure 5e) and was confirmed by a 3.5-fold increase in secreted VEGF as measured by ELISA. This elevation of VEGF and the other angiogenic factors in the low pH-exposed GSC-depleted cultures resulted in a secreted protein profile that was very similar to that of GSCs cultured at normal pH (Figures $5 a$ and d).

To further evaluate whether the increase in VEGF protein was due to an increase in VEGF transcription, we determined VEGF mRNA levels using quantitative real-time PCR. We found that low $\mathrm{pH}$ increased VEGF mRNA $\sim 2$ - to 20 -fold depending on the glioma cells tested in both GSC-enriched and -depleted cultures (Figure 5g; Supplementary Figure 8A). Together, these data demonstrate that promotion of VEGF and other angiogenic factors can be due to transcriptional changes in response to acidic stress. Furthermore, exposure to an acidic microenvironment is likely to contribute to tumor growth and maintenance through promotion of a GSC-like angiogenic phenotype.

Induction of HIF2 $\alpha$ and HIF target genes by acidic stress. The most well-characterized pathway that regulates angiogenesis and VEGF involves the hypoxia response factors (HIFs). We therefore sought to evaluate HIF2 $\alpha$ and HIF $1 \alpha$ gene expression in our low pH-treated glioma cells. In GSC-enriched cultures, we found that HIF2 $\alpha$ mRNA was increased greater than threefold in three different GSC preparations (Figure 6a; 
a

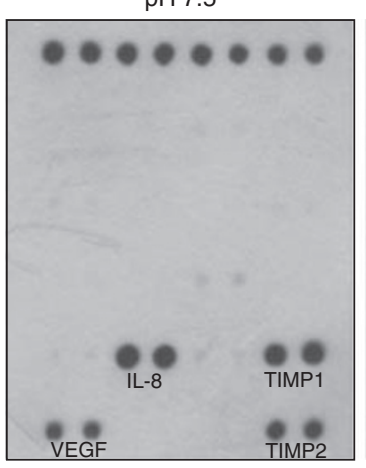

pH 6.5

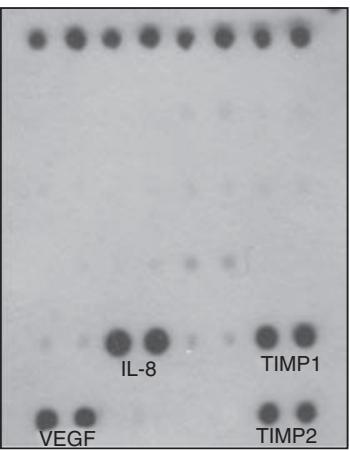

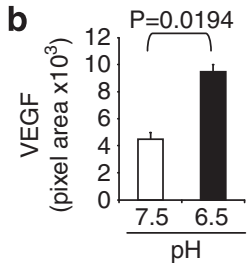

c

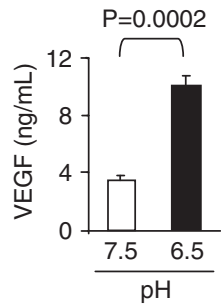

T1863 GSC Depleted

d

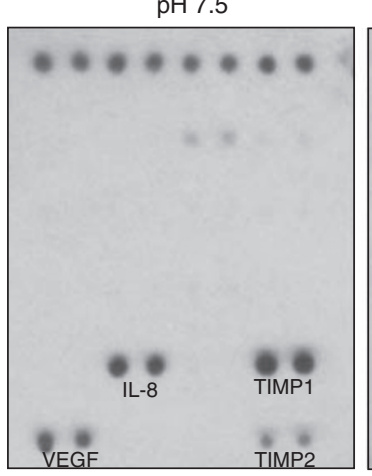

$\mathrm{pH} 6.5$

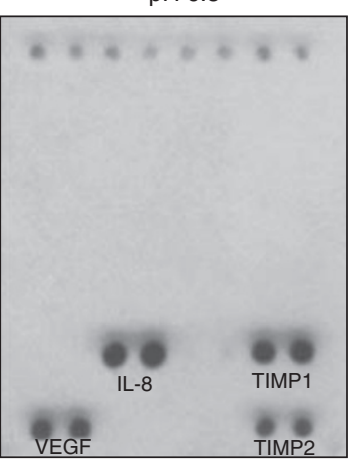

e

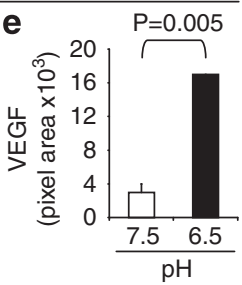

f

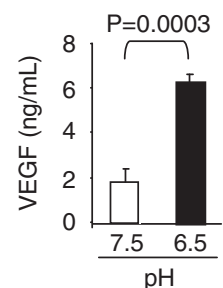

g

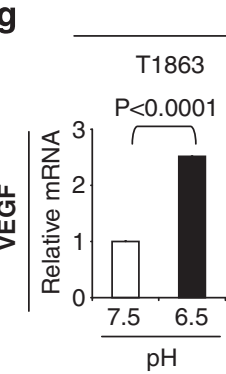

GSC Enriched

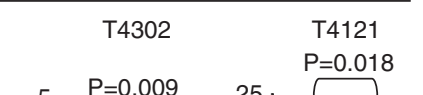

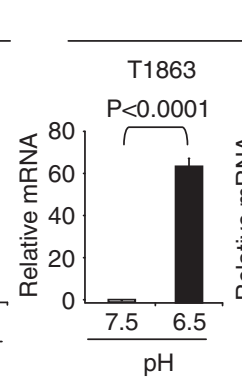

GSC Depleted

T4302 T4121
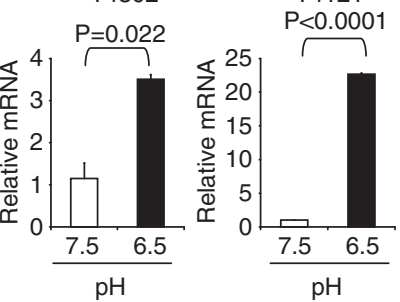

Figure 5 Treatment with low pH increases expression of angiogenic factors including VEGF in both GSC-enriched and -depleted cultures. (a) Human Angiogenesis Arrays demonstrate differential expression of angiogenic factors in the conditioned media of GSCs isolated from a T1863 glioma xenograft and pretreated at pH 7.5 or $\mathrm{pH} 6.5$ for 6 days. (b) Image $\mathrm{J}$ quantification of the expression of VEGF on the Human Angiogenesis Array in (a). (c) ELISA demonstrates elevated VEGF protein expression in the conditioned media of T1863 GSCs pretreated with media at pH 6.5. $n=2$. (d) Human Angiogenesis Arrays demonstrate differential expression of angiogenic factors in the conditioned media of GSC-depleted cultures isolated from a T1863 glioma xenograft and pretreated at pH 7.5 or pH 6.5. (e) Image J quantification of the expression of VEGF on the Human Angiogenesis Array in (d). (f) ELISA demonstrates elevated VEGF protein expression in the conditioned media of T1863 GSC-depleted cultures pretreated at $\mathrm{pH}$ 6.5. $n=2$. (g) Real-time PCR demonstrates increased VEGF mRNA in GSC-enriched or -depleted cultures isolated from T1863, T4302 or T4121 xenografts. $n=2$ for each tumor type. RNA was collected after 6 days of treatments with media at pH 6.5 or pH 7.5 using Qiagen RNAeasy kits. RNA was reverse transcribed and analyzed for VEGF using real-time PCR

Supplementary Figure 8B). In contrast, we observed variable effects on HIF1 $\alpha$ mRNA with either a minimal induction or more potent and statistically significant repression (Figure 6b; Supplementary Figure $8 \mathrm{C}$ ). As our lab and others previously determined that HIF2 $\alpha$ is a GSC marker and that increased HIF2 $\alpha$ mRNA is characteristic of GSCs, ${ }^{6,7}$ the promotion of HIF2 $\alpha$ by exposure to acidic stress suggests that low $\mathrm{pH}$ facilitates GSC maintenance. 
Similar to these results, HIF $2 \alpha$ mRNA was increased greater than sevenfold in every GSC-depleted culture exposed to low pH (Figure 6c) whereas HIF1 $\alpha$ mRNA was repressed (Figure $6 \mathrm{~d}$ ). These data suggested that HIF2 $\alpha$ may be the HIF primarily responsible for VEGF induction in acidic conditions. However, HIFs are most well known for being regulated at the level of protein stability and $\mathrm{HIF} 1 \alpha$ protein has been shown to be stabilized under reduced $\mathrm{pH}^{21}$ We therefore determined whether the changes in HIF
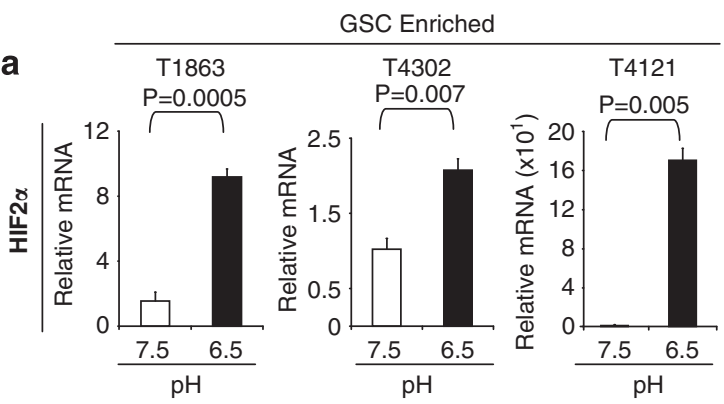

b
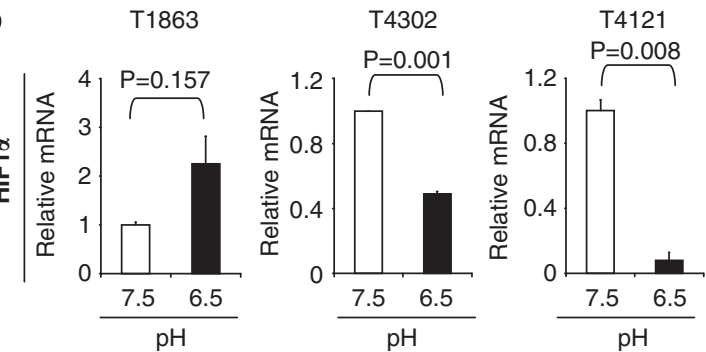

C

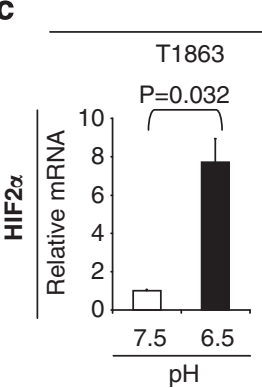

GSC Depleted
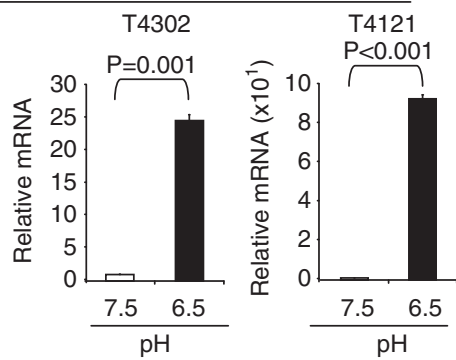

d
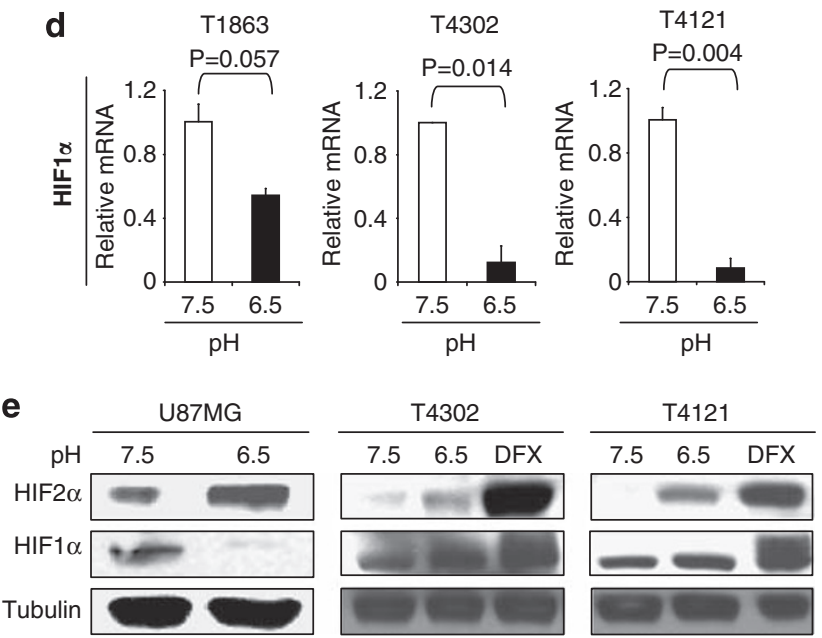

transcription were sufficient to induce changes in protein expression using western analysis. We confirmed that HIF2 $\alpha$ protein was dramatically increased with low $\mathrm{pH}$ treatment of a glioma cell line or two different cultures of GSC-depleted cells (Figure 6e). In contrast, HIF1 $\alpha$ protein expression was either decreased or relatively unchanged after acidic stress (Figure 6e). Consistent with our previous reports, ${ }^{6,8}$ the hypoxia mimetic desferrioxamine (DFX) was sufficient to induce both HIF $1 \alpha$ and HIF2 $\alpha$ in GSC-depleted cultures (Figure 6e). Thus, low pH preferentially elevates HIF2 $\alpha$ mRNA and protein in glioma cells. Considering our previous data that HIF2 $\alpha$ overexpression in GSC-depleted cultures is sufficient to promote tumorigenesis, ${ }^{8}$ these data suggest that elevation of HIF2 $\alpha$ may be one mechanism through which an acidic microenvironment promotes tumor growth.

To determine whether the elevation of HIF2 $\alpha$ protein induced changes in gene expression, we characterized levels of two genes, which were previously shown to be HIF2 $\alpha$ dependent and regulate cancer cell growth or survival: glucose transporter type 1 (Glut1) and the proteinase inhibitor SerpinB9.,22,23 Both Glut1 and SerpinB9 may be upregulated in cancer cells to facilitate cell growth or survival, ${ }^{24,25}$ indicating there may be functional consequences of the dysregulation of these genes in glioma. We found that low $\mathrm{pH}$ induced Glut1 $30 \%$ or more (Figure 7a). SerpinB9 was also induced by low $\mathrm{pH}$ threefold or more in three different GSC preparations (Figure 7b). Similar to the potent induction of HIF2 $\alpha$ in GSC-depleted cells, Glut1 and SerpinB9 were induced more than fourfold in all glioma cells tested (Figures $7 c$ and $d$ ). These data strongly suggest that an acidic microenvironment can produce a specific elevation of $\mathrm{HIF} 2 \alpha$, which promotes the expression of known HIF target genes, including VEGF, Glut1 and SerpinB9. Together, our data demonstrate that the production of VEGF and the increase in tumorigenesis resulting from low $\mathrm{pH}$ is due to the promotion of a cancer stem cell phenotype, which is likely dependent, in part, on the elevation of HIF $2 \alpha$.

We next sought to determine whether this promotion of a cancer stem cell phenotype by acidic stress could be reverted by exposure to a non-acidic $\mathrm{pH}$. Similar to our previous results, we found that acidic stress induced the expression of HIF2 $\alpha$ and the HIF2 $\alpha$ target genes VEGF, Glut1 and SerpinB9 in D456MG GSC-depleted cultures (Figure 8). However, culture at $\mathrm{pH} 7.5$ after exposure to $\mathrm{pH} 6.5$ was sufficient to prevent maintenance of the induction of HIF2 $\alpha$ and most of its

Figure 6 Exposure to low pH induces HIF2 $\alpha$ mRNA. (a and $\mathbf{b}$ ) Expression of HIFs was evaluated in CD133 + enriched (a and $\mathbf{b})$ or CD133 + depleted (c and $\mathbf{d}$ ) cells isolated from three different human glioma xenografts and subsequently treated with acidic ( $\mathrm{pH}$ 6.5) or normal ( $\mathrm{pH} 7.5)$ cell culture media for 6 days. RNA was collected using Qiagen RNAeasy kits, reverse transcribed and analyzed for HIF2 $\alpha$ (a) or HIF1 $\alpha$ (b) using real-time PCR. $n=2$ for each tumor type. (c) HIF2 $\alpha$ mRNA increases in T1863, T4302 and T4121 GSC-depleted cultures exposed to pH 6.5 compared with those cultured at $\mathrm{pH}$ 7.5. (d) Exposure to low $\mathrm{pH}$ represses HIF1 $\alpha$ mRNA in T1863, T4302 and T4121 GSC-depleted cultures. (e) Western analysis demonstrates that HIF2 $\alpha$ protein is elevated after treatment with acidic media. Totalcell lysates were collected from the human glioma cell line U87 MG or GSC-depleted cultures isolated from T4302 and T4121 xenografts treated with media at pH 6.5 or pH 7.5 for 14 days. In GSC-depleted cultures, addition of $100 \mu \mathrm{M}$ of the hypoxia mimetic desferrioxamine (DFX) in pH 7.5 media was included as a positive control for HIF expression. Equivalent amounts of total protein were analyzed with the indicated antibodies. Tubulin expression was used as a loading control 
a

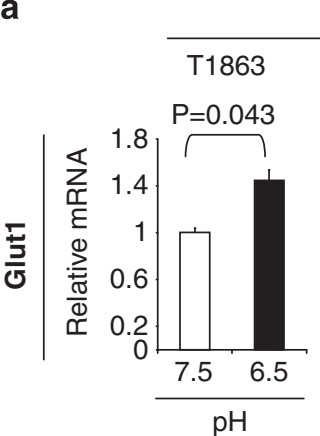

GSC Enriched
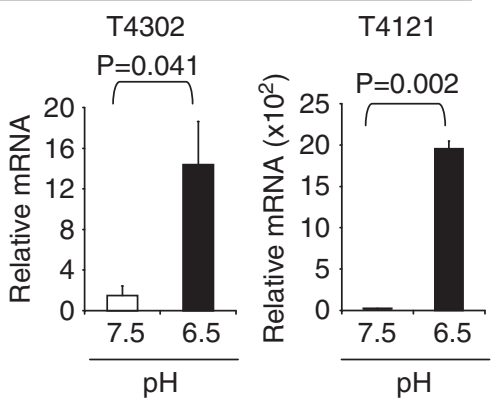

b
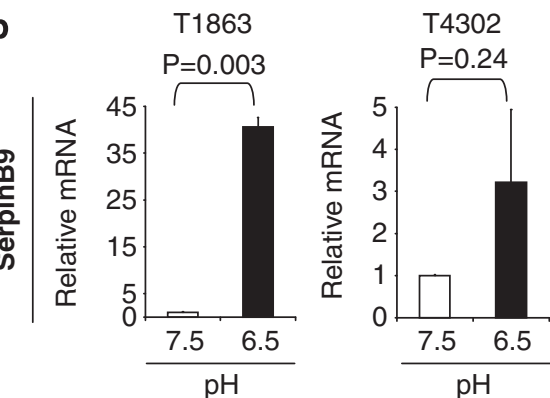

T4121

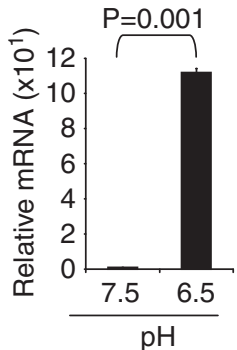

C

GSC Depleted

\section{T1863}

T4302

$\mathrm{T} 4121$
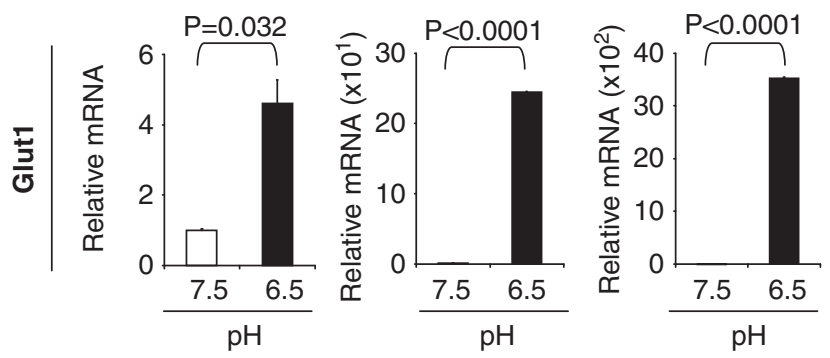

d
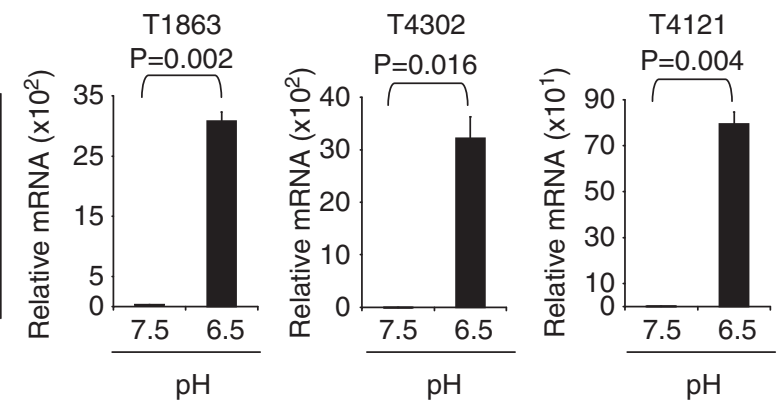

Figure 7 Low $\mathrm{pH}$ treatment increases the expression of the HIF2 $\alpha$ target genes Glut1 and SerpinB9. mRNA expression was evaluated in CD133+ enriched ( $\mathbf{a}$ and $\mathbf{b}$ ) or CD133 + depleted (c and $\mathbf{d}$ ) cells isolated from three different human glioma xenografts and subsequently treated with acidic $(\mathrm{pH} \mathrm{6.5)}$ or normal $(\mathrm{pH} 7.5)$ cell culture media for 6 days. RNA was collected using Qiagen RNAeasy kits, reverse transcribed and analyzed for the Glut1 $\alpha$ (a and $\mathbf{c}$ ) or SerpinB9 (b and $\mathbf{d})$ using real-time PCR. $n=2$ for each tumor type

targets (Figure 8). Similarly, we found that expression of the GSC markers Olig2 and Nanog was also reduced to near baseline levels by restoration of a non-acidic $\mathrm{pH}$ (Supplementary Figure 4). These data suggest that tumor cell plasticity towards a GSC phenotype may be reduced by targeting intratumoral $\mathrm{pH}$.
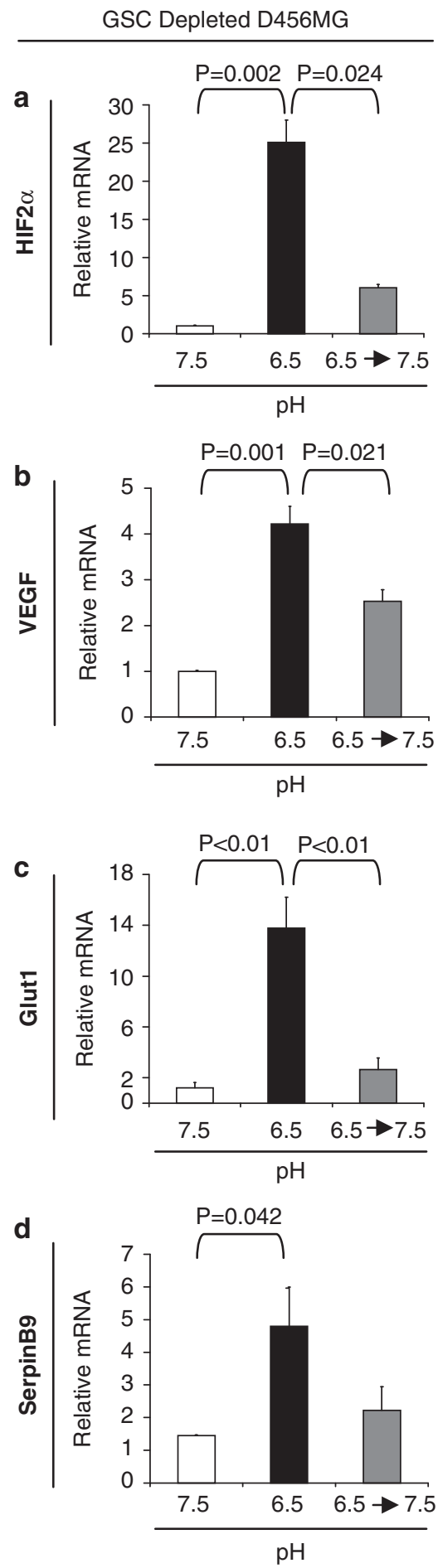

Figure 8 Promotion of HIF2 $\alpha$ and HIF2 $\alpha$ target genes by acidic stress can be reverted by increasing $\mathrm{pH}$. CD133 - cells isolated from D456 MG xenografts were exposed to acidic ( $\mathrm{pH} \mathrm{6.5)} \mathrm{or} \mathrm{typical} \mathrm{(} \mathrm{pH} 7.5$ ) cell culture media for a total of 10 days. After the initial 6 days, cells exposed to acidic $\mathrm{pH}$ were subsequently exposed to $\mathrm{pH}$ $7.5(6.5 \rightarrow 7.5)$ for 4 days. RNA was collected using Qiagen RNAeasy kits, reverse transcribed and analyzed for the specific genes indicated using real-time PCR. $n=3$. mRNA expression of HIF2 $\alpha$ (a), VEGF (b), Glut1 (c) and SerpinB9 (d) are elevated in cells treated with acidic stress. Restoration to $\mathrm{pH} 7.5$ significantly decreases levels of most HIF2 $\alpha$ target genes over the time course evaluated 


\section{Discussion}

The elevated metabolism of rapidly growing tumors results in the consumption of energy from a variety of carbon sources. During this process, hydrogen ions as well as acidic metabolites including lactic acid and carbonic acid are produced. These acidic products are actively transported to the extracellular space via cell membrane-associated complexes including $\mathrm{Na}+/ \mathrm{H}+$ exchangers, monocarboxylate transporters (MCT), $\mathrm{Na}+\mathrm{HCO}_{-}-$transporters and $\mathrm{Cl}-/ \mathrm{HCO} 3-$ exchangers. Although often considered to be constitutively expressed, oncogenes may induce exchanger activity and/ or expression, indicating the potential for transformation to promote hydrogen ion export. ${ }^{26,27}$ Once hydrogen ions and acidic metabolites are extracellular, they may be removed via the vasculature. However, the combination of elevated acidic metabolite production and poor tumor circulation often results in accumulation of hydrogen ions and a resulting drop in intratumoral $\mathrm{pH}^{12,15}$

Published reports and our data demonstrating the reduced $\mathrm{pH}$ of human gliomas and their xenografts demonstrate that acidic $\mathrm{pH}$ is an important microenvironmental component of brain tumors. ${ }^{12,13}$ However, cell culture media have a slightly alkaline $\mathrm{pH}$ at baseline and are designed to maintain a relatively neutral $\mathrm{pH}$ during cellular growth. Standard culture conditions therefore cannot accurately represent the acidic microenvironment of human tumors and are likely to underestimate the importance of low $\mathrm{pH}$ conditions on tumor cell signaling and behaviors. Considering our findings that acidic stress promotes the GSC phenotype and other studies linking hypoxia to GSCs, culture under reduced oxygen tension and $\mathrm{pH}$ may be a more appropriate model to facilitate in vitro maintenance of the cellular heterogeneity found in vivo.

Tumor growth and angiogenesis are tissue-specific processes regulated by the microenvironment, which includes acidic $\mathrm{pH}$ in solid tumors. Although our data demonstrate that the growth of gliomas is enhanced by exposure of implanted cells to acidic stress, changes were most apparent in the orthotopic intracranial, rather than subcutaneous, model. These differences may be due to distinctions in the tumor microenvironment and vasculature between these sites. For example, VEGF isoforms have been shown to have divergent activities in the promotion of tumor angiogenesis depending on the location of glioma cell implantation with greater effects on intracranial rather than subcutaneous tumor growth. ${ }^{28}$ HIF's effects on the growth of transformed astrocytes also differ depending on whether cells are implanted subcutaneously or intracranially. ${ }^{29}$ Furthermore, implantation of glioma cells at different anatomical sites differentially regulates ligands for the integrins, ${ }^{30}$ known as GSC regulators. ${ }^{31}$ These data strongly suggest that distinctions in the tumor microenvironment may explain the differences in statistical significance observed with subcutaneous and intracranial tumor cell implantations.

The molecular mechanisms through which an acidic microenvironment could promote the GSC phenotype remain to be fully determined, but we have identified acquisition of HIF2 $\alpha$ as an important contributor. HIF $1 \alpha$ and HIF2 $\alpha$ are most well known for being regulated at the level of protein stability through ubiquitination by the Von Hippel Lindau (VHL) tumor suppressor gene and subsequent targeting for proteasomal degradation. Although previous studies suggested that HIF $\alpha$ may be stabilized under low $\mathrm{pH}$ through nucleolar sequestration of $\mathrm{VHL},{ }^{22}$ we did not observe significant changes in $\mathrm{HIF} 1 \alpha$ protein in glioma cells due to exposure to acidic $\mathrm{pH}$. In contrast, HIF2 $\alpha$ mRNA and protein were strongly upregulated, suggesting a critical role for this HIF $\alpha$ in an acidic microenvironment. These data further support recent studies delineating non-redundant functions for HIF $2 \alpha$ and HIF $1 \alpha$ in brain tumors and GSCs. ${ }^{6,7,22}$ HIF2 $\alpha$-specific target genes, including Oct4, Glut1 and SerpinB9, ${ }^{23,32}$ which were increased by low $\mathrm{pH}$, are elevated in GSCs. ${ }^{6}$ In addition to directly binding target gene promoters, HIF $\alpha$ may promote the transcription of important stem cell factors through epigenetic modifications. Recent studies demonstrate that $\mathrm{HIF} \alpha$ can induce the Jumonji family of histone demethylases to promote chromatin modification and tumor growth. ${ }^{33-36}$ It would therefore appear likely that changes in histone methylation could also result from HIF2 $\alpha$ induction in acidic microenvironments. Thus, further exploration of the differential roles for HIF2 $\alpha$ in stem cell and cancer biology, including epigenetic modifications, is warranted.

The ability of tumor microenvironmental conditions such as low $\mathrm{pH}$ to influence the GSC phenotype strongly suggests that it will be critical to target the GSC niche as well as GSCs directly. Targeting of GSC-specific molecular targets such as HIF2 $\alpha$ is likely to be beneficial. However, removal of these GSCs may provide opportunistic space in the GSC niche for other tumor cells, which will then be exposed to hypoxia, acidic $\mathrm{pH}$, or other as yet undefined GSC-promoting microenvironmental conditions (e.g. metabolic derangements). Subsequent to GSC directed therapies, microenvironmental cues in the GSC niche may then re-establish a subset of GSCs to maintain tumor cell homeostasis. If, however, GSCs and the GSC niche were targeted concurrently, GSCs may be eliminated along with tumor cell plasticity to a more GSC-like phenotype, as has been proposed in other models. ${ }^{5,10}$

One mechanism through which an acidic microenvironment may be targeted is through restoration of a neutral $\mathrm{pH}$ in growing tumors. A recent study in a breast cancer model demonstrated that treatment with sodium bicarbonate could be sufficient to increase tumor extracellular $\mathrm{pH}^{37}$ Increasing the $\mathrm{pH}$ of breast tumors was associated with reduced invasion, ${ }^{37}$ a property associated with CSCs in breast cancer. $^{38}$ Similar results were determined in a computer simulation of the ability of system buffers to reduce extracellular $\mathrm{pH}^{39}$ Our data also demonstrate that restoring a nonacidic $\mathrm{pH}$ to cells exposed to acidic stress can reduce the elevation of HIF2 $\alpha$ and other GSC markers induced by low $\mathrm{pH}$. Although further experiments are needed, these data suggest the utility of targeting the acidic microenvironment as an anticancer stem cell therapy.

\footnotetext{
Materials and Methods

Measurement of intratumoral extracellular pH. An Orion 98-63 micro-pH electrode (Thermo Electron Corporation, Marietta, OH, USA), a 16-gauge beveled tip electrode (1.6 mm OD) coupled to an Orion 310 PerpHecT pH meter (Thermo Electron Corporation), was used to measure intratumoral $\mathrm{pH}$. The beveled $\mathrm{pH}$ probe was inserted transcutaneously into the tumors. Measurements were taken in the edge and central region of the tumors as well as in the tumor-free subcutaneous region of the posterior cervical midline.
} 
Isolation of cells and culture with pH treatment. Matched cultures enriched or depleted for GSCs were isolated from primary human brain tumor patien specimens or human glioblastoma xenografts as previously described, in accordance with a Duke University or Cleveland Clinic Institutional Review Board Protocol complying with national regulatory standards, with patients signing informed consent. ${ }^{6,40,20}$ Isolated cells were separated by a magnetic sorting column using microbead-conjugated CD 133 antibodies. We found that CD133 + cells fulfilled the functional criteria of GSCs, including expression of GSC markers, self-renewal, multi-lineage differentiation and tumor propagation. To assess effects of low $\mathrm{pH}$, media $\mathrm{pH}$ was altered with hydrochloric acid in accordance with previously published protocols. ${ }^{18}$ Non-stem tumor cells were cultured in a DMEM/Neurobasal media adjusted to $\mathrm{pH} 7.5$ or pH 6.5 containing $5 \% \mathrm{FBS}$, $5 \mathrm{ng} / \mathrm{ml} \mathrm{bFGF}$, and $5 \mathrm{ng} / \mathrm{ml} \mathrm{EGF}$ and media were changed every other day for the indicated times. For stem cell maintenance studies, GSCs were cultured in Neurobasal adjusted to $\mathrm{pH} 7.5$ or $\mathrm{pH} 6.5$ containing $10 \mathrm{ng} / \mathrm{ml}$ bFGF and $10 \mathrm{ng} / \mathrm{ml} \mathrm{EGF}$, and media was changed every other day.

Semiquantitative PCR. PCR was performed on CDNA generated by Superscript III reverse transcriptase (Invitrogen, Carlsbad, OH, USA) from total RNA harvested from cells using RNAeasy Kit (Qiagen, Valencia, CA, USA) with indicated primers as previously described. ${ }^{6,8}$

Immunofluorescence. Immunofluorescence of isolated cells was performed similar to our previous description ${ }^{6}$ using antibodies against GFAP (Sigma, St Louis, MO, USA), Nanog (Santa Cruz, Santa Cruz, CA, USA) and $\beta$ III tubulin (Millipore, Billerica, MA, USA).

Angiogenesis antibody array. Conditioned media were harvested from the indicated cells pretreated for 6 days with the indicated $\mathrm{pH}$ and then cultured in identical media without growth factors for $24 \mathrm{~h}$. TranSignal Human Angiogenesis Antibody Arrays (Panomics, Santa Clara, CA, USA) were twice incubated with $2 \mathrm{ml}$ of conditioned media for $1.5 \mathrm{~h}$ and then processed according to the manufacturer's instructions as previously described. ${ }^{20}$ Intensity of protein expression was quantified with ImageJ software, where indicated with the total mean intensity equal to the area multiplied by the mean intensity.

VEGF ELISA. Human VEGF Quantikine ELISA kits (R\&D Systems, Minneapolis, MN, USA) were used according to the manufacturer's instructions and our previous reports ${ }^{6,20}$ with conditioned media harvested from cells pretreated for 6 days with the indicated $\mathrm{pH}$ and then cultured in identical media without growth factors for $24 \mathrm{~h}$

In vivo tumor formation. Intracranial orthotopic and subcutaneous transplantation of cells under specific $\mathrm{pH}$ conditions into nude mice was performed as described in accordance with a Cleveland Clinic Institutional Animal Care and Use Committee approved protocol concurrent with national regulatory standards as previously described. ${ }^{6,40,20}$ Briefly, cells were counted after 6 days of exposure to indicated $\mathrm{pH}$ and 5000 cells were implanted into the right frontal lobes of athymic BALB/C nu/nu mice. Mice were maintained until the development of neurological symptoms. Tumors were subsequently frozen or paraffin embedded and stained with hematoxylin and eosin or for CD31 (BD Pharmingen, San Diego, CA, USA) with DAB Peroxidase kits (Vector Laboratories, Burlingame, CA, USA).

Statistical analysis. Descriptive statistics were generated for all quantitative data with presentation of means \pm standard error. Significance was tested by unpaired $t$-test using GraphPad InStat 3.0 software (GraphPad Software Inc., La Jolla, CA, USA)or, when variances were significantly different, by one-way analysis of variance of log-transformed data using MedCalc software (MedCalc Software, Mariakerke, Belgium). For in vivo studies, Kaplan-Meier curves and logrank analysis were performed using MedCalc software.

\section{Conflict of interest}

The authors declare no conflict of interest.

Acknowledgements. Financial support was provided by the Goldhirsh Foundation, McDonnell Foundation, and NIH grants NS054276, CA116659, CA129958, CA154130 (JR). AH is supported by a grant from the National Brain
Tumor Association and by NIH grant CA151522. JDL is supported by a National Research Service Award (CA142159) and an American Brain Tumor Association Fellowship (Sponsored by the Joelle Syverson Fund).

1. Furnari FB, Fenton T, Bachoo RM, Mukasa A, Stommel JM, Stegh A et al. Malignant astrocytic glioma: genetics, biology, and paths to treatment. Genes Dev 2007; 21: 2683-2710.

2. Stupp R, Mason WP, van den Bent MJ, Weller M, Fisher B, Taphoorn MJ et al. Radiotherapy plus concomitant and adjuvant temozolomide for glioblastoma. N Engl J Med 2005; 352: 987-996.

3. Reya T, Morrison SJ, Clarke MF, Weissman IL. Stem cells, cancer, and cancer stem cells. Nature 2001; 414: 105-111.

4. Park DM, Rich JN. Biology of glioma cancer stem cells. Mol Cells 2009; 28: 7-12.

5. Calabrese C, Poppleton H, Kocak M, Hogg TL, Fuller C, Hamner B et al. A perivascular niche for brain tumor stem cells. Cancer Cell 2007; 11: 69-82.

6. Li Z, Bao S, Wu Q, Wang H, Eyler C, Sathornsumetee $\mathrm{S}$ et al. Hypoxia-inducible factors regulate tumorigenic capacity of glioma stem cells. Cancer Cell 2009; 15: 501-513.

7. Seidel S, Garvalov BK, Wirta V, von Stechow L, Schänzer A, Meletis K et al. A hypoxic niche regulates glioblastoma stem cells through hypoxia inducible factor 2 alpha. Brain 2010; 133 (Pt 4): 983-995.

8. Heddleston JM, Li Z, McLendon RE, Hjelmeland AB, Rich JN. The hypoxic microenvironment maintains glioblastoma stem cells and promotes reprogramming towards a cancer stem cell phenotype. Cell Cycle 2009; 8: 3274-3284.

9. Soeda A, Park M, Lee D, Mintz A, Androutsellis-Theotokis A, McKay RD et al. Hypoxia promotes expansion of the CD133-positive glioma stem cells through activation of HIF-1alpha. Oncogene 2009; 28: 3949-3959.

10. Rosen JM, Jordan CT. The increasing complexity of the cancer stem cell paradigm. Science 2009; 324: 1670-1673

11. Kallinowski $F$, Vaupel $P$. pH distributions in spontaneous and isotransplanted rat tumours. Br J Cancer 1988; 58: 314-321.

12. Vaupel $P$, Kallinowski $F$, Okunieff $P$. Blood flow, oxygen and nutrient supply, and metabolic microenvironment of human tumors: a review. Cancer Res 1989; 49: 6449-6465.

13. Gerweck LE, Seetharaman K. Cellular pH gradient in tumor versus normal tissue: potential exploitation for the treatment of cancer. Cancer Res 1996; 56: 1194-1198.

14. Gatenby RA, Gillies RJ. Why do cancers have high aerobic glycolysis? Nat Rev Cancer 2004; 4: 891-899.

15. Chiche J, Brahimi-Horn MC, Pouysségur J. Tumour hypoxia induces a metabolic shift causing acidosis: a common feature in cancer. J Cell Mol Med 2010; 14: 771-794.

16. Fukumura D, Xu L, Chen Y, Gohongi T, Seed B, Jain RK. Hypoxia and acidosis independently up-regulate vascular endothelial growth factor transcription in brain tumors in vivo. Cancer Res 2001; 61: 6020-6024.

17. Xu L, Fukumura D, Jain RK. Acidic extracellular $\mathrm{pH}$ induces vascular endothelial growth factor (VEGF) in human glioblastoma cells via ERK1/2 MAPK signaling pathway: mechanism of low pH-induced VEGF. J Biol Chem 2002; 277: 11368-11374.

18. Reichert M, Steinbach JP, Supra $P$, Weller M. Modulation of growth and radiochemosensitivity of human malignant glioma cells by acidosis. Cancer 2002; 95: 1113-1119.

19. Mashima T, Sato S, Sugimoto $Y$, Tsuruo T, Seimiya H. Promotion of glioma cell survival by acyl-CoA synthetase 5 under extracellular acidosis conditions. Oncogene 2009; 28: 9-19.

20. Bao S, Wu Q, Sathornsumetee S, Hao Y, Li Z, Hjelmeland AB et al. Stem cell-like glioma cells promote tumor angiogenesis through vascular endothelial growth factor. Cancer Res 2006; 66: 7843-7848.

21. Mekhail K, Gunaratnam L, Bonicalzi ME, Lee S. HIF activation by pH-dependent nucleolar sequestration of VHL. Nat Cell Biol 2004; 6: 642-647.

22. Holmquist-Mengelbier $\mathrm{L}$, Fredlund $\mathrm{E}$, Lofstedt $\mathrm{T}$, Noguera $\mathrm{R}$, Navarro $\mathrm{S}$, Nilsson $\mathrm{H}$ et al. Recruitment of HIF-1alpha and HIF-2alpha to common target genes is differentially regulated in neuroblastoma: HIF-2alpha promotes an aggressive phenotype. Cancer Cell 2006; 10: 413-423.

23. Keith B, Simon MC. Hypoxia-inducible factors, stem cells, and cancer. Cell 2007; 129: 465-472

24. Macheda ML, Rogers S, Best JD. Molecular and cellular regulation of glucose transporter (GLUT) proteins in cancer. J Cellular Physiol 2005; 202: 654-662.

25. van Houdt IS, Oudejans JJ, van den Eertwegh AJ, Baars A, Vos W, Bladergroen BA et al. Expression of the apoptosis inhibitor protease inhibitor 9 predicts clinical outcome in vaccinated patients with stage III and IV melanoma. Clin Cancer Res 2005; 11: 6400-6407.

26. Kaplan DL, Baron WF. Long term Expression of $\mathrm{c}-\mathrm{H}$-ras stimulates $\mathrm{Na}-\mathrm{H}$ and $\mathrm{Na}+$ dependent Cl-HCO3 exchange in NIH-3T3 fibroblasts. J Biol Chem 1994; 269: 4116-4124.

27. Reshkin SJ, Bellizzi A, Caldeira S, Albarani V, Malanchi I, Poignee $\mathrm{M}$ et al. $\mathrm{Na}+/ \mathrm{H}+$ exchanger-dependent intracellular alkalinization is an early event in malignant transformation and plays an essential role in the development of subsequent transformation-associated phenotypes. FASEB J 2000; 14: 2185-2197.

28. Guo P, Xu L, Pan S, Brekken RA, Yang ST, Whitaker GB et al. Vascular endothelial growth factor isoforms display distinct activities in promoting tumor angiogenesis at different anatomic sites. Cancer Res 2001; 61: 8569-8577. 
29. Blouw B, Song H, Tihan T, Bosze J, Ferrara N, Gerber HP et al. The hypoxic response of tumors is dependent on their microenvironment. Cancer Cell 2003; 4: 133-146.

30. Gladson CL, Wilcox JN, Sanders L, Gillespie GY, Cheresh DA. Cerebral microenvironment influences expression of the vitronectin gene in astrocytic tumors. J Cell Sci 1995; 108: 947-956.

31. Lathia JD, Gallagher J, Heddleston JM, Wang J, Eyler CE, MacSwords J et al. Integrin alpha 6 regulates glioblastoma stem cells. Cell Stem Cell 2010; 6: 421-432.

32. Covello KL, Kehler J, Yu H, Gordan JD, Arsham AM, Hu CJ et al. HIF-2alpha regulates Oct4: effects of hypoxia on stem cell function, embryonic development, and tumor growth. Genes Dev 2006; 20: 557-570

33. Pollard PJ, Loenarz C, Mole DR, McDonough MA, Gleadle JM, Schofield CJ et al. Regulation of Jumonii-domain-containing histone demethylases by hypoxia-inducible factor (HIF)-1alpha. Biochem J 2008; 416: 387-394.

34. Wellmann S, Bettkober M, Zelmer A, Seeger K, Faigle M, Eltzschig HK et al. Hypoxia upregulates the histone demethylase JMJD1A via HIF-1. Biochem Biophys Res Commun 2008; 372: 892-897.
35. Krieg AJ, Rankin EB, Chan D, Razorenova O, Fernandez S, Giaccia AJ. Regulation of the histone demethylase JMJD1A by hypoxia-inducible factor 1 alpha enhances hypoxic gene expression and tumor growth. Mol Cell Biol 2010; 30: 344-353.

36. Yang J, Ledaki I, Turley H, Gatter KC, Montero JC, Li JL et al. Role of hypoxia-inducible factors in epigenetic regulation via histone demethylases. Ann N Y Acad Sci 2009; 1177: 185-197.

37. Robey IF, Baggett BK, Kirkpatrick ND, Roe DJ, Dosescu J, Sloane BF et al. Bicarbonate increases tumor pH and inhibits spontaneous metastases. Cancer Res 2009; 69: 2260-2268.

38. Sheridan C, Kishimoto H, Fuchs RK, Mehrotra S, Bhat-Nakshatri P, Turner $\mathrm{CH}$ et al. CD44+/CD24- breast cancer cells exhibit enhanced invasive properties: an early step necessary for metastasis. Breast Cancer Res 2006; 8: R59.

39. Silva AS, Yunes JA, Gillies RJ, Gatenby RA. The potential role of systemic buffers in reducing intratumoral extracellular pH and acid-mediated invasion. Cancer Res 2009; 69: 2677-2684

40. Bao S, Wu Q, McLendon RE, Hao $Y$, Shi $Q$, Hjelmeland $A B$ et al. Glioma stem cells promote radioresistance by preferential activation of the DNA damage response. Nature 2006; 444: 756-760

Supplementary Information accompanies the paper on Cell Death and Differentiation website (http://www.nature.com/cdd) 